\title{
Discussions on the Teaching Reform of College Mathematics Curriculum Based on the Training of Applied Talents
}

\author{
Dong Guangqian \\ School of mathematics and statistics, Longdong University, Qingyang, China, 745000
}

Keywords: applied talents; college mathematics; teaching reform

\begin{abstract}
The university is the place to cultivate high quality and comprehensive applied talents for the society. With the continuous promotion of quality education, the teaching of college mathematics curriculum is paid more attention. The purpose of university mathematics teaching is not only to let students understand mathematics knowledge, but let them master mathematics knowledge, cultivate mathematical literacy, scientific literacy and entrepreneurial spirit of innovation, to adapt to the social production practice better, meet the development demand of the applied talents. However, in practical teaching, the teaching effect is not ideal due to factors such as teachers' professional level and examination evaluation. Therefore, it is particularly important to implement individualized teaching and optimize teaching means [1].
\end{abstract}

The cultivation of applied talents is the inevitable transformation of social development, education, college mathematics teaching in higher education to cultivate applied talents training objectives plays an important role in cultivating students' thinking quality education. With the help of science education means, the transformation of advanced knowledge of the students into fruit can make the students increase comprehensive theoretical and practical ability, earlier to participate in scientific research and social practice. But the premise is to optimize the teaching reform, create the education mechanism that integrates the students' knowledge, quality and ability in one, and effectively improve the problems in teaching.

\section{The significance of the teaching reform of the course}

The training of traditional applied talents pays attention to the cultivation of professional ability and neglects the cultivation of basic ability, which leads to the low rate of graduate employment and the low competitiveness of the society, which not only fails to meet the requirements of applied talents, but also wastes educational resources. In accordance with the previous educational experience, it is particularly critical to strengthen the students' basic abilities in accordance with the training goals of applied talents. Mathematics, as the foundation of the knowledge of various professional disciplines, has profound scientific connotation, which plays an important role for the students to understand, contact and transform the society. The students' learning mathematics can cultivate strict orderliness and thinking, which can promote the improvement of students' comprehensive quality. The mathematics department, especially the non mathematics specialty, plays an important basic role in understanding, combing and cultivating the scientific literacy of the students [2].

Line generation and probability are important courses for students to master mathematical tools. They play a fundamental role in shaping students' personality, rational thinking and other mathematical literacy, ability and knowledge system. In the aspect of training applied talents, they should be differentiated from research talents. The former requires students to have core mathematical thinking, comprehensive ability of mathematical theory and practice, and pay attention to knowledge application. The latter pays attention to the mastery of students' mathematical thinking and theoretical knowledge. All the students should pay more attention to the accumulation of basic knowledge and the training of thinking. We should strictly focus on the needs of the social development for applied talents, innovate the teaching reform of the university mathematics curriculum, and improve the students' social competitiveness. 
The course teaching after the education reform should start with the comprehensive training direction of the students' knowledge, accomplishment and ability. Based on knowledge analysis, students should master basic concepts, methods, computing skills and concepts of mathematics, laying the foundation for further knowledge development. Based on the quality training, students should have good self-study habits and dare to question the knowledge of mathematics. It has the quality of seeing the essence through the phenomenon, and can solve the problems in the life with mathematical rational thinking, and can simplify the problem from many angles through the mathematical model. Based on the ability, it is necessary to cultivate the ability of thinking, thinking, solving and innovating practice.

\section{The status quo of the training of applied talents}

It is mainly embodied in three aspects, first of all, in the course setting, professional courses occupy a great proportion, and the proportion of college courses is less. The public basic curriculum is the main medium for the training of applied talents. The basic curriculum is set less in class hours, and the goal of training talents is ignored directly. Secondly, it is recognized that teachers' understanding of the training of applied talents is not in place, including the knowledge, ability and quality training structure, and the personnel training specifications are directly ignored. It is not clear about the teaching plan and syllabus, which directly leads to the derailment of the training goal of the applied talents. To understand the teaching requirements, to adjust the teaching plan reasonably and to ensure the teaching effect is particularly key. Finally, teachers are influenced by traditional educational concepts, emphasizing knowledge imparting, emphasizing teaching theory and logic, instilling mathematical formulas and concepts, ignoring students' application ability in mathematics knowledge. In the course of the education of students' knowledge and methods, they do not pay attention to the understanding of the students' essence of mathematics, so that the students will not be able to connect with them [3].

First of all, the educational value of the teaching materials is low, and it has always quoted the textbook of mathematics in the last century, paying more attention to the reasoning and discussion of the students. Professional knowledge than it is too narrow, the teaching content in professional practice is not to use, out of touch with the basic teaching, students are not aware of the importance of learning mathematics. Secondly, the teachers are not able to expand the teaching knowledge to avoid the confusion of students' knowledge. Most of the teachers will not update the content of the course teaching. In order to catch up with the teaching progress, the teaching method is single, the ancient board, the lack of interaction between teachers and students. In addition, the basic tools of mathematics have not been realized, and the basic knowledge, ability and accomplishment of each professional student are not thoroughly studied. In addition, the level of teachers' comprehensive literacy is not high, which leads to low teaching efficiency. At the same time, teachers do not flexibly use modern teaching methods, showing a single discipline characteristics, which does not conform to the development standard of teaching and education, resulting in the quality of teaching derailment can not be guaranteed. The final assessment and evaluation system of the ancient board, can not really help teachers and students to adjust the "teaching", "learning" model.

The content of mathematics is logical and abstract. It requires students to have rational analysis, logical reasoning and multi angle dialectic ability, which is not easy to master. But in fact, students' learning problems are mainly reflected in the following aspects. First, the students who just entered the university campus are not clear about the training objectives of mathematics teaching and their future development direction, and not clear learning goals directly affect interest and motivation in learning. At the same time, teachers didn't adjust their teaching mode according to their training objectives according to the principle of "student-centered". They neglected the cultivation of students' independent and independent learning ability, and their interest in learning was not high. They did not develop in accordance with the direction of applied talents. Secondly, the students have great differences in mathematics foundation, lack of self-study, study the spirit actively, and do not have the learning methods and skills. Finally, the students' learning time is limited and the teaching progress is accelerated, which leads to the one-sided knowledge of knowledge and the 
decline of self-restraint ability [4].

\section{Teaching reform measures}

Teaching reform needs to focus on whether students really learn knowledge, improve learning ability, and solve problems effectively, and weaken teachers' teaching content, students' knowledge, and knowledge infusion. In addition, the teaching contents, syllabus and teaching methods are used to meet the students' development needs, professional training goals and students' ability to accept. The curriculum system, the teaching material system and the teaching resources are restructured in an all-round way, and the teaching methods and means are fully optimized. In addition, the training of talents should pay more attention to the training of professional skills and cultural knowledge, and should pay more attention to quality education, that is, personality cultivation. After the teaching reform, we need to classify and grade teaching. The former focuses on the characteristics of students' professional enrollment, and in accordance with the service concept, we should clarify the emphasis of mathematics teaching and teach students in accordance with their aptitude. The latter refers to the design of the teaching schedule according to the differences between the students' basis and the difference in the teaching process of the various majors.

The syllabus should be in accordance with the goal of professional training. The teaching contents are divided according to different majors, and made diversified, multi class syllabus, a class of physics; computer, electronic and mechanical engineering, electrical automation professional class; chemistry, food, biological fields; industry and commerce, information, tourism and other professional class syllabus. There are also differences in different teaching materials, teaching contents and teaching classes. Finally, students choose the course free, according to the professional requirements, we choose the course [3] which is difficult and difficult to teach [5].

Based on the teaching materials, first teachers can make flexible choices and improvements according to the teaching task, so that they can meet the students' receiving ability and knowledge level. The proof of the main conclusions of the individual at the same time, derivation and answer skills can not do an important story, as in "to explain the complex functions", can seize the complex function, the mapping concept of key problems, application example teaching method for how to explain the application of problem, the definition of complex variable function can fade because of its one yuan and the real variable function definition, as long as one yuan of real variable function definition of "real", "complex" can be transformed into. Finally, the mathematical knowledge of the university is repeated with high school mathematics knowledge, and the teaching process can be desalinated, such as the monotonous judgment. To explain the knowledge that can not be connected, such as the knowledge of the new triangle polar coordinate transformation. The flexible treatment of the teaching content can promote the structure of students' knowledge structure.

First of all, teachers should have correct teaching ideas and educational ideas, and pay attention to the flexible use of teaching methods.

Secondly, according to the students' cognitive characteristics and basic level, the characteristics of the mathematical knowledge, the teaching purpose, the teaching content and the teaching depth are chosen. In the teaching, the knowledge background, the introduction of examples, the guidance of thinking and the multi - level exercise are introduced. When explaining "probability", we can introduce the actual background of the origin of probability, restore the essence of the concept, and excavate the implied mathematical thought. In theory, we should pay attention to the analysis of thinking and the inspiration of thinking, so that we can guess the knowledge content and the way of thinking before we grasp the mathematical conclusion, and integrate the associative result and the book knowledge, so that we can master the mathematical thinking correctly. The basic theory of mathematical knowledge combined with practical examples, including the application of probability theory in the lottery "," the application of probability and statistics in the lottery "and other practical examples, the cultivation of students' mathematical thinking and application ability, the feeling should be combined with the actual significance to the mathematical theory of knowledge and life.

Using flexible teaching methods, such as in the "line" to explain the generation, use of multimedia teaching method, or group discussion, flipping the classroom, double teacher teaching, 
let students better understand the exchange law, combined with rate of addition, and the specific definition of distributive law, distributive law, the number of factor 1 by law number by two operations. Among the incomprehensible knowledge points, such as "double integral", considering the factors such as inverted teaching time, students' understanding ability and limited teacher level, the key part can be made into network video. Online inform students to update knowledge, so that students can download and watch anytime and anywhere, web search for keywords is more conducive to the development of knowledge. At the same time, teachers and students can communicate online, give students' weaknesses more examples to guide the application of their mathematical ideas, so that their academic achievements can be improved together. In order to enable students to master more advanced mathematical computing methods, teachers can guide students to use MATLAB, Mathematica, maple and other mathematical software, so that students can easily carry out numerical calculation, symbolic operation, formula deduction, and then train students' mathematical culture. In addition, in the actual teaching, we should actively guide the student modeling and other learning skills, and enrich the students' ability to practice and innovate [6].

Finally, the practice teaching is carried out, and the training goal of the applied talents is centered, and the students' innovation and the training of the hands-on ability are emphasized. According to the teaching curriculum system and the knowledge structure, the practical teaching content is determined. If the teacher is explaining the knowledge points of random variables, let students reverse design questions according to the answers to the examples in the text, learn to draw inferences or draw inferences from them, or design related application questions according to the concept and combining with the reality of life. It can ensure the students' grasp of basic knowledge, and strengthen the ability of computing, logical thinking, comprehensive analysis and solving problems and space imagination. In addition, the expansion of knowledge can also enrich the knowledge of the students. As a teacher, teachers should have the ability to combine theory and practice.

Based on the assessment, the first assessment content is to the evaluation of students to master the basic knowledge, this examination content should be emphasized in the daily teaching contents and basic methods, calculation, application, the concept of consistent, cannot explain the pianti, such as simplified and middle school mathematics knowledge content repeat. Secondly, we should strengthen daily assessment work, take attendance rate, classroom performance and homework completion as daily assessment items, enhance students' learning urgency, help students develop good learning habits, and at the same time, take students' daily academic achievements as the main. Finally, the proportion of examination results was divided reasonably, for example, the proportion of daily examination results accounted for $30 \%$, and in the period of the period and the end of the period accounted for $35 \%$, respectively.

Based on the evaluation system, evaluation can help students develop, especially the personalized development, and at the same time, help students unite and help each other to ensure the authenticity and reliability of the evaluation results. At the same time, we pay more attention to the problem solving process at the same time, and have received extensive attention from the educational system. Developmental evaluation is more suitable for the purpose of applied talents education. It involves comprehensive, feedback principles and so on. The evaluation contents, ways and the diversity of subjects can enable students to improve continuously through induction and encouragement at the original level. First of all, in the content of evaluation, discipline, learning enthusiasm, learning effect and so on are the main evaluation contents of the classroom performance. Self learning, extracurricular application and group discussion are the main contents of after-school learning. Secondly, the subject of evaluation, teachers, students themselves, and the study group are all evaluation subjects. The main evaluation methods include performance evaluation, classroom assessment, portfolio assessment, etc. the evaluation methods include qualitative evaluation, quantitative evaluation, self evaluation and others evaluation. The academic evaluation is mainly comprehensive evaluation, that is, the comprehensive evaluation of the students' quality and ability and knowledge. According to the results of subjective, objective and 
dynamic evaluation, we can timely feedback to students, let students realize their own shortcomings, and adjust learning plans and future development goals.

\section{Conclusions}

Curriculum teaching is the key stage of talent training. Once we change the past teaching concept, we should adhere to the student centered approach and teach students in accordance with their aptitude according to their individual differences. The teaching materials, teaching methods and teaching contents are optimized around the specialized courses. In order to improve the status of education assessment and evaluation, the reform of the teaching and education of college mathematics curriculum should be carried out around the training program of applied talents.

\section{References}

[1] Liu Y, Qian H, Hu L, et al. Discussion of Dye Chemistry Curriculum Teaching Reform Based on Applied Talents Training[J]. Shandong Textile Economy, 2014.

[2] Li H E, Liu G J. Discussion on Teaching Reform of Database Technology Curriculum as the Goal of Training Applied Talents [J]. Computer Knowledge \& Technology, 2012.

[3] Wang J Q. Research on Physical Education Curriculum Based on the Training Applied Talents in Higher Vocational Colleges [J]. Bulletin of Sport Science \& Technology, 2014.

[4] Hui L I. New Exploration of Applied Talents Cultivating Model: Based on Curriculum Reform of Elementary School Mathematics Teaching Methods [J]. Journal of Hezhou University, 2013.

[5] Wen Z P. Teaching Reform Based on The Training of Engineering Talent in Computer Network Curriculum [J]. Computer Education, 2008.

[6] Wang Y. On the Curriculum Reform of Art Design Specialty: Based on the Talents Training of Fashion Marketing and Media [J]. Journal of Huaihai Institute of Technology, 2012. 